\title{
The Effects of Technological Acquisition on Innovation Performance - Analyzing from the Perspective of Technical Characteristics
}

\author{
Canjun Chen
}

\begin{abstract}
Based the perspective of technology, this paper investigates how technological acquisition affect post-acquisition innovation by distinguishing the dimensions of similarity and complementarity of technology between acquired company and acquiring company. The results shows there is an inverted-U relationship between similar technology and post-acquisition innovation, and there is an $U$ relationship between complementary technology and post-acquisition innovation .In addition, the size of knowledge base of acquirer has an adjustment function. It will moderate the relationship between the similar technology and post-acquisition negatively; and it will moderate the relationship between the complementary technology and post-acquisition positively.
\end{abstract}

Index Terms-Technological acquisition, innovation, technical similarity, technical complementarity.

\section{INTRODUCTION}

In the case of economic globalization, capital, information, talents and other factors have flowed frequently, and market competition has intensified. It is difficult for enterprises to rely on the previous scale effect to form a monopoly position.

As the the control of technology in a company becoming more and more important in current marketplace, technological innovation is the critical factor of sustainable development.

Since 2016, many companies in China has set off a wave of overseas mergers and acquisitions, and the total transaction value has reached 200 billion US dollars. However, $20 \%$ of companies are high-tech industries, and the main goals of these acquisition are to obtain technology and knowledge that they lacked. Consequently, the technological acquisition plays an important role in R\&D of these companies [1]-[3].Also, it can be seen the driving of technological factors will become the main target of mergers and acquisitions with the arrival of digital and high-tech industries in the future development of enterprises.

Innovation is seen as the result of using existing knowledge to produce new applications [4]. Due to the blockade of external technology and fierce competition in the market, company is difficult to achieve rapid innovation in the short term for relying on the combination of internal knowledge only. Therefore, acquiring had become a mainstream trend to acquire technical knowledge from the outside through the way of acquisition. However, whether

Manuscript received May 9, 2019; revised August 2, 2019.

Canjun Chen is with the Hohai University, China (e-mail: 905407297@qq.com). the acquired company will bring positive innovation effects to the merger and acquisition is related to the quantity and knowledge characteristics of the knowledge technologies. External knowledge often has its own specific combination, so whether the acquirer can follow the route of its technology research and development and carry out new exploration is of vital importance to the absorption and integration of external technical knowledge. Under this assumption, the relationship between the two sides' own knowledge base and fault tolerance can greatly affect subsequent innovation activities. Therefore, acquire needs to pay close attention to the scale and characteristics of the knowledge base of acquired company in acquiring external technology [5].

\section{LITERATURE REVIEW}

Although the mean to enhance the innovation ability of companies by mergers and acquisitions has become the approach pursued by many companies [3], the key factors that whether acquires realize the success of the subsequent integration and continuous innovation of their technology depend on the knowledge base possessed by both parties. There are many factors affecting the introduction of technology, such as the overlap of knowledge base, the knowledge embedding model, the M\&A motivation, and the differences of policy and cultural [6], [7]. Specifically, these studies are devided into two categories. The one is to reaserch the question of consolidation in both parties after mergers and acquisitions from the perspective of external management. Another is to study the characteristics of knowledge technology between acquire and acquired, which are main to explore the mechanism of technology combination and the direction of R\&D in the next stage from an internal perspective. In the first category, there are a lot of studies on the two fields. For example, Jeffrey et al. [8] analyzed the synergistic innovation effect of the post-merger company from the perspective of resource allocation, and the author believes that the difference in resource allocation pattern is more conducive to the subsequent synergy innovation effect. Seru et al. [9] suggest that mergers and acquisitions are easy to divert the attention of managers, which will weaken the company's attention in R\&D, resulting in low efficiency of innovation. From the perspective of employee motivation, Zenger and Rahul et al. [10], [11] who use incentive theory to study the impact of the changes of corporate structure on the incentives of R\&D employee They conclude incentive is an important factor in promoting internal cooperation and research and the company has an 
advantage in measuring the performance and manage technical staff compared with large companies. Pratim et al. [12] make a radical and gradual distinction between the enterprise's knowledge base and innovative ideas, using software companies as the analysis sample. Then, he held that the radical knowledge base is not conducive to absorption and will hinder later innovation process, and the acquire will reduce the time to develop new products if the acquired is relate to the acquire in knowledge bases. However, some scholars suggest that the similarity of knowledge between acquire and acquired will have a negative impact on innovation in the future. The reason to propose this view is that the similarity of technology forms the laziness of R\&D, which will result in the redundancy of knowledge and reduce the novelty of exploring new technologies [13].

In summary, while there enough published reports on technology acquisition, but few studies have studied on the knowledge characteristics of M\&A, and the results of researching in case-analysis are one-sided. Therefore, it is difficult to form mainstream conclusions, especially in the lack of corresponding theoretical analysis on the knowledge scale of both parties. Therefore, this paper based on the perspective of similarity and complementarity of technical knowledge and combines its knowledge scale to make a deeply analysis in theory and empirical .And it will provide reference for subsequent related researches .The main contributions of this paper are as follows: First, in the field of technology merger and acquisition, we study the impact of similar and complementary technical knowledge on subsequent innovation performance by subdividing the characteristics of knowledge and expand the previous studies in conclusion deep. Second, we open up a new path in the selection of variables, measuring the value of the patent and use the measurement result to assess the ability of knowledge innovation. This method is more accurate than previous study that only use the number of the patents as the ability of innovation. Thirdly, that using the information asymmetry theory and the perspective of the knowledge absorption and integration of both parties explain the mechanism of the influence of knowledge characteristics on innovation performance detailly. Further, on this basis, we discuss the role of knowledge scale on the moderating effect of knowledge characteristics.

\section{THEORETICAL BACKGROUND AND HYPOTHESES}

\section{A. Knowledge Characteristics and Innovation Performance}

According to the research of Makri et al. [13], the knowledge similarity between companies refers to the extent to which technical problems are solved in the same narrow knowledge domain. While the complementarity refers to the degree of resolution in different narrow areas of knowledge in the field of exploration where both parties have a common wide range of knowledge. Such division is conducive to the analysis of some industries of high-tech. For example, in some communications and electronics industries, the types of knowledge of these industries are cumulative, and their innovation process are coherent and heterogeneous. So, when acquiring external related knowledge, it is still difficult to further promote the innovation activities even though that knowledges are similar to the acquirer.

In the events of acquisition, it is a kind of normal phenomenon that acquire have trouble in subsequent integration due to there are information asymmetry between acquirer and acquired. When the acquirer acquires the knowledge of the target company, the acquire has difficulty in evaluating the relevant knowledge and products accurately because of the agency problem. As the position of being acquired, they take for granted that conceal its own technical defects and the actual cost of conversion into products for getting more benefit. Since the R\&D process of the company is in a state of secrecy, it will exacerbate the phenomenon that the acquired deceive the acquirer. However, there has a solution to this problem if the two parties have a similar knowledge base in technology. For acquirer, they have adequate understanding of the knowledge characteristics of the target company before acquiring. The acquirer will have a high degree of awareness of the technical nature and assess product value of the acquired accurately. Likewise, it is difficult for the acquired to conceal its own technical defects so that the risk of inaccurate evaluation due to information asymmetry is greatly reduced.

During the process of $\mathrm{R} \& \mathrm{D}$, the ideas of technical design and the various structures in company are depended by each other, and all of them are the part of the knowledge base. For the similarity of technology of two sides, they will have similarities in the process of R\&D. Later, they can combine existing knowledge and management systems with external knowledge and establish "sub-additive cost synergy" together. In this situation, acquirer will reduce the cost of R\&D., and similar knowledge base and cognitive systems increase the likelihood of resource absorption and mutual learning. Another, the similarity of technology means that the two sides have similarities in the design of some technical concepts, and which will decreases disagreements in the process of $R \& D$.Therefore, the acquirer shortens the time in exploring new products and accelerate the progress of innovation. However, if the knowledge introduced by the acquired is similar to the existing knowledge, it will easily lead to knowledge redundancy. Moreover, in the process of $\mathrm{R} \& \mathrm{D}$, the high degree of similarity of technology will increase the dependence of $R \& D$ path. Excessive path dependence will easily reduce the novelty of technological innovation. When internal technology is upgraded to boundary, the synergy effect will be weakened. For these reasons, we expect that:

Hypothesis 1: Without considering other factors, technical similarity will positively promote innovation of the acquirer at first in the technical acquisition, but the effect will be weakened as the degree of similarity of technology increases. So, the relationship between technology similarity and innovation performance shows an inverted U-shaped

Additionally, the result of the innovation performance is exactly opposite to technical similarity for technical complementary in acquirer and acquired party. The complementarity of knowledge between the two parties means that they are in different dimensions in the field of science and technology. So, after acquiring the external 
complementary technology, the acquirer needs to spend vast cost to integrate in the early stage. And it should be more difficult than the situation of similar technology in terms of technology absorption and transformation. Then, it will make company to achieve synergistic innovation in a short period of time hardly. However, with the level of complementarity increasing and continued investment in R\&D constantly, the complementary technical of the company increases the market of the introduction of new technologies or products. Furthermore, the acquirer expands the reserves of internal knowledge and increases the effect of collaborative innovation latterly for the high level of complementarity technology. This situation promoted the possibility of innovative activities to explore success greatly. For these reasons, we expect that:

Hypothesis 2: Without considering other factors, technology complementarity will temporarily inhibit the innovation of the acquirer at first in the technical acquisition. But with the continuous investment in $R \& D$, the synergistic innovation effect will become more obvious. So, the relationship between technology complementarity and innovation performance shows an positive U-shaped.

\section{B. The Regulatory Effect of Knowledge Scale}

The scale of knowledge and the types of technology of company mean that the breadth and depth of its mastery of technology in certain field, and it is an important basis for subsequent technology integration and exploring new kinds of technology.

When the resemble degree are high between acquirer and acquired and the acquirer has a larger knowledge base than acquired, it will accelerate the process of transition and absorption of knowledge and technology from acquired and the weakness of the synergistic innovation effect will easily appear prematurely for acquirer. When the knowledge base of the acquirer is larger than the target company, due to its rich knowledge base, it is not necessary to invest too much technical resources to absorb external technology in the process of technology transition. That will reduce the range of collaborative innovation effects of radiation for lack of communication. Comparing to the whole process of innovation activities of the company, the innovative effects are limit to the benefits of acquirer after acquiring similar technologies. Because the acquirer with large knowledge will have a perfect process of internal R\&D in management, the acquire needs to adjust their own structure in order to couple with external technologies. This situation will form redundancy of knowledge and reduce the function of synergistic innovation effect in the process of $R \& D$. For these reasons, we expect that:

Hypothesis 3: The scale of knowledge technology has negative regulation function on the relationship between the technological similarity and innovation performance. Concretely, it will hinder the subsequent innovation performance if the acquirer of knowledge base is larger than the acquire after $M \& A$.

However, it will produce an opposing effect comparing if the acquirer has a larger knowledge base than the target company in the M\&A that the degree of complementation in both sides are too high. When the acquirer has acquired the complementary knowledge, it need invest more resource to integrate that knowledge than the situation that the knowledge is similar. But it will increase the change of interaction between the two sides in technology exchange and learning, and it will help to achieve further breakthroughs and improvements in technology or products. Particularly, these companies with large scale of knowledge base have ability to digest external complementary knowledge, and it helps companies to have a good in the value of that knowledge. Consequently, this type of M\&A increases the technical dimension of company innovation and the possibility of breakthrough in the original technology. For these reasons, we expect that:

Hypothesis 4: The scale of knowledge technology has positive regulation function on the relationship between the technological complementarity and innovation performance. Concretely, it will promote the subsequent innovation performance if the acquirer of knowledge base is larger than the acquire after $M \& A$.

\section{METhODS AND DATA}

\section{A. Selection of Samples and Measurement}

The sample companies selected in the article are from public companies which have disclosed the accidents of M\&A in China. Considering that the performance of technology in some industries such as services is not obvious for it is the research on the technological innovation ability after the merger. For this reason, the scope of the selected enterprises comes from the technology-intensive industries such as manufacturing and communication.

Dependent variable (IE). The problem explored in this paper is the impact of the knowledge base of both sides on the follow-up innovation performance of M\&A. In the existing literatures, most of the innovation performance are measured by the number of patents. In view of the traits of each enterprise in a certain field and the variety of patent types, the number of patents are difficult to evaluate the value of the technology fundamentally and distinguish the actual innovation ability of the enterprise. However, the patent value is defined by factors such as market attractiveness, market coverage, technical quality and $\mathrm{R} \& \mathrm{D}$ cost. Therefore, we use exact value of every patent by taking advantage of these factors in order to measure the ability of innovation precisely. In this paper, the value of each patent is measured by State Intellectual Property Office and the Wisdom Bud website as the innovative performance of the company.

Independent variables. We use the level of technical similarity, complementarity and knowledge scale of the two parties as the dependent variable, and still use the patent as the basis of the enterprise knowledge level. In the International Patent Classification, patents are divided into 8 categories, 24 divisions, and 119 major categories. Each category has its own corresponding patent serial number. It means that the level of technical similarity is too high if there are many numbers of patents in the same serial number between the acquirer and acquired. We also followed Makri et al. [14] to construct measures of technology similarity/complementarity based on patent data of the 
acquirer and target firm. Technology similarity is calculated as the number of patents applied for by the acquirer (A) and the target $(\mathrm{T})$ that are in the same patent class, multiplied by the total number of patents the acquirer has in all common classes divided by total acquirer patents. Hence, technology similarity is given by:

Technology similarity $(T S)=$ (Overlap all patent classes/ Total patents A\&T) * (Total acquirer patents in common classes/ Total acquirer patents)

Technology complementarity is calculated using the number of patents in the same category but in different patent classes, and given by:

Technology complementarity $(T C)=($ Overlap all patent categories/ Total patents A\&T)-(Overlap all patent categories/ Total patents A\&T)*(Total acquirer patents in common categories/ Total acquirer patents)

Relative knowledge scale (RKS): About the assessment of scale of the knowledge, we use the result of the measurement of the value of these patents. Further, the relative knowledge scale is represented by which the patent value of the acquirer is divided by the patent value of the target company. It means that the acquirer has larger knowledge scale than acquired If the ratio is greater than one.

Control variables: There are is relatively more standardized at the management level in these large-scale companies. For these technical staff, standardized management will help companies to carry out activities of R\&D. Another, the higher of growth means the company has a stronger ability of profitability, it helps company retain talents easily. Considering that the innovation of the enterprise is related to the investment, management and the enterprise growth, we use the company's scale (Size), R\&D intensity (RD) and growth capacity of enterprises (Growth) as control variables in this paper.

\section{B. Model Construction}

In order to facilitate the operation, the related data are logarithm analysis in advance. This paper uses multiple regression analysis method to construct the following multiple regression model (TS, TC, RKS represent the Technology similarity, Technology similarity, Technology complementarity, Relative knowledge scale).

$\mathrm{TC}^{2}$ and $\mathrm{TS}^{2}$ represent the curvilinear effect of technological similarity and complementarity on innovation performance. In order to verify the moderating effect of relative knowledge regulation between mergers and acquisitions, the interaction term is introduced to detect the moderating effect. As shown below:

$$
\begin{aligned}
& \mathrm{IE}=\beta_{0}+\beta_{1} \times \mathrm{TS}+\beta_{2} \times \mathrm{TC}+\beta_{3} \times \mathrm{RKS}+\beta_{4} \times \mathrm{TS}^{2}+\beta_{5} \times \\
& \mathrm{TC}^{2}+\beta_{6} \times \mathrm{RD}+\beta_{7} \times \text { Growth }+\beta_{8} \times \text { Size } \\
& \mathrm{IE}=\beta_{0}+\beta_{1} \times \mathrm{TS}+\beta_{2} \times \mathrm{TC}+\beta_{3} \times \mathrm{RKS}+\beta_{4} \times \mathrm{TS}^{2}+\beta_{5} \times \\
& \mathrm{TC}+\beta_{6} \times \mathrm{RD}+\beta_{7} \times \text { Growth }+\beta_{8} \times \text { Size }+\beta_{9} \times \mathrm{TS} \times \mathrm{RKS} \\
& \mathrm{IE}=\beta_{0}+\beta_{1} \times \mathrm{TS}+\beta_{2} \times \mathrm{TC}+\beta_{3} \times \mathrm{RKS}+\beta_{4} \times \mathrm{TS}^{2}+\beta_{5} \times \\
& \mathrm{TC}^{2}+\beta_{6} \times \mathrm{RD}+\beta_{7} \times \text { Growth }+\beta_{8} \times \text { Size }+\beta_{9} \times \mathrm{KC} \times \mathrm{KL}
\end{aligned}
$$

\section{EMPIRICAL}

\section{A. Relevance Analysis}

In Table I, the level of correlation between the variables is not high, most of the correlation coefficients are below 0.4 . Knowledge similarity is negatively correlated with complementarity and negatively correlated with enterprise knowledge scale and asset value. In order to further detect whether there is collinearity between variables, the differential expansion factor VIF is tested. It is found that the average VIF of independent variables is less than 4 , so the collinearity problem can be eliminated.

TABLE I: COEFFICIENT OF CORRELATION AMONG VARIABLES

\begin{tabular}{|c|l|c|c|c|c|c|}
\hline Variable & TC & TS & RKS & Size & R\&D & Growth \\
\hline TC & 1 & & & & & \\
\hline TS & $-0.351^{* *}$ & 1 & & & & \\
\hline RKS & $0.183^{*}$ & $-0.111^{*}$ & 1 & & & \\
\hline Size & $0.145^{*}$ & $-0.166^{*}$ & $0.211^{*}$ & 1 & & \\
\hline R\&D & $0.074^{*}$ & $-0.172^{* *}$ & 0.352 & $0.576^{*}$ & 1 & \\
\hline Growth & $0.079^{* *}$ & $0.062^{* *}$ & $0.247^{*}$ & $0.675^{*}$ & $0.533^{*}$ & 1 \\
\hline
\end{tabular}

\section{B. Regression Analysis}

Table II is the result of regression analysis among variables. Because of the existence of quadratic terms, we use the way of White's heteroscedasticity and residual analysis chart to detect the question. The results show that it does not exist the question of heteroscedasticity and autocorrelation of residual. Consequence, the result of regression model is effective. In model 1, the coefficient estimate of TS is positive and significant $(\mathrm{p}<0$.05) while the coefficient

\begin{tabular}{|c|c|c|c|}
\hline Variable & Model1 (IE) & Model2(IE) & Model3(IE) \\
\hline TS & $\begin{array}{c}0.369^{* *} \\
(2.315)\end{array}$ & $\begin{array}{c}0.407^{\text {**** }} \\
(3.216)\end{array}$ & $\begin{array}{c}0.376^{* * *} \\
(1.988)\end{array}$ \\
\hline $\mathrm{TC}$ & $\begin{array}{c}-0.751^{* *} \\
(-1.861)\end{array}$ & $\begin{array}{l}-0.633^{* *} \\
(-2.453)\end{array}$ & $\begin{array}{l}-0.517^{* *} \\
(-2.31)\end{array}$ \\
\hline RKS & $\begin{array}{c}0.199^{* *} \\
(2.215)\end{array}$ & $\begin{array}{c}0.127^{* *} \\
(2.341)\end{array}$ & $\begin{array}{l}0.121^{* *} \\
(3.214)\end{array}$ \\
\hline $\mathrm{TS}^{2}$ & $\begin{array}{l}-0.741^{* *} \\
(-2.681)\end{array}$ & $\begin{array}{l}-0.611^{* * * *} \\
(-2.952)\end{array}$ & $\begin{array}{l}-0.436^{* * * k} \\
(-3.213)\end{array}$ \\
\hline $\mathrm{TC}^{2}$ & $\begin{array}{l}0.704^{* * *} \\
(4.211)\end{array}$ & $\begin{array}{l}0.812^{* * *} \\
(4.123)\end{array}$ & $\begin{array}{l}0.855^{* * *} \\
(3.768)\end{array}$ \\
\hline TS* RKS & & $\begin{array}{l}-0.245^{* *} \\
(-2.241)\end{array}$ & \\
\hline $\begin{array}{l}\mathrm{TC}^{*} \\
\mathrm{RKS} \\
\end{array}$ & & & $\begin{array}{c}0.258^{*} \\
(1.764)\end{array}$ \\
\hline $\mathrm{RD}$ & $\begin{array}{c}0.311^{* *} \\
(2.513)\end{array}$ & $\begin{array}{c}0.245^{\text {** }} \\
(2.142)\end{array}$ & $\begin{array}{c}0.146^{*} \\
(1.523)\end{array}$ \\
\hline Growth & $\begin{array}{c}0.261 \\
(1.213)\end{array}$ & $\begin{array}{c}0.541 \\
(1.411)\end{array}$ & $\begin{array}{c}0.306 \\
(0.995)\end{array}$ \\
\hline Size & $\begin{array}{c}0.687 \\
(0.326)\end{array}$ & $\begin{array}{c}0.537 \\
(0.234)\end{array}$ & $\begin{array}{c}0.215 \\
(0.512)\end{array}$ \\
\hline $\mathrm{R} 2$ & 0.668 & 0.613 & 0.742 \\
\hline $\mathrm{F}$ & 4.8 & 4.31 & 5.76 \\
\hline
\end{tabular}
estimate of TC is negative and significant ( $p<0.05)$. However, the coefficient estimate of the two variable in their quadratic terms have opposite result. Hypothesis 1 and hypothesis 2 are preliminarily verified.

TABLE II: REGRESSION RESULTS

in parentheses.

In model 1, 2 and 3, the coefficient estimate of RKS in the three models are positive and significant $(p<0$.05). It shows that the acquirer who has a lager of knowledge base will be 
conducive to the absorption and integration of external knowledge and technology. In model 2 and model 3, it is verified that the scale of knowledge has regulative effect on the similarity and complementarity of technology. The coefficient estimate of the interaction of TS with RKS is negative and significant $(\mathrm{p}<0 \quad .05)$. It means that the knowledge scale of the acquirer has a negative moderating effect on the relationship between technology similarity and innovation performance. Hypothesis 3 is verified. On the contrary, the coefficient estimate of the interaction of TC with RKS is positive and significant ( $p<0.05)$. It means that the knowledge scale of acquirer plays a positive role in regulating the technology complementarity and innovation performance of both sides. Hypothesis 4 is verified

\section{CONCLUSION}

This paper has analysed the impact of knowledge similarity, knowledge complementarity and scale of knowledge on the innovation of acquirer after M\&A. By combining relevant theories and empirical analysis of some listed companies' events of M\&A in China, we conclude that the relationship between innovation performance level of the similarity of technological knowledge between acquirer and target company is inverted, while relationship between innovation performance level of the complementary of technological knowledge positive U-shaped. Another, the knowledge scale of the acquirer has negative and positive moderating effects on the relationship between technological similarity and complementary with innovation performance respectively.

Although there has some literature which has analyzed technology mergers from the perspective of the type of knowledge, most of them are based on related and irrelevant events of acquisition. The dimension of knowledge division is too broad in these papers. However, the small gap of technology plays an important role in the follow-up innovation effect in high-tech intensive industries. The research of this paper subdivides the knowledge dimension of both sides of M\&A and makes a detailed reasoning on the influence mechanism of the follow-up innovation of M\&A by combining with the systematic analysis of knowledge scale. It provides the corresponding theoretical and practical reference for China's enterprises in technology M\&A. However, there are still some shortcomings in the article. There are many factors affecting the technological innovation of enterprises, the conclusions drawn from the analysis of the article from the perspective of knowledge are not comprehensive for the reason of the limitations of samples and the occlusion of some operational information of listed companies. Accordingly, we can provide more abundant theory and conclusion from the perspective of the culture and development strategy of the enterprises of both sides of M\&A in the follow-up study.

\section{CONFLICT OF INTEREST}

The authors declare no conflict of interest.

\section{AUTHOR CONTRIBUTIONS}

We break down the characteristics of knowledge and study the impact of similarity and complementarity of technical knowledge on subsequent innovation performance.

\section{REFERENCES}

[1] S. Lodh and M. R. Battaggion, "Technological breadth and depth of knowledge in innovation: The role of mergers and acquisitions in biotech," Industrial and Corporate Change, vol. 24, no. 2, pp. 383-415, 2014.

[2] G. M. Phillips and A. Zhdanov, "The incentives from merger and acquisition activity," Review of Financial Studies, vol. 26, no. 1, pp. 34-75, 2013

[3] J. Bena and K. Li, "Corporate innovations and mergers and acquisitions," The Journal of Finance, vol. 69, no. 5, pp. 1923-1960, 2014.

[4] L. Fleming and O. Sorenson. "Technology as a complex adaptive system: Evidence from patent data," Research Policy, vol. 30, no. 7, pp. 1019-1039, 2001.

[5] G. Ahuja and R. Katila, "Technological acquisitions and the innovation performance of acquiring firms: A longitudinal study," Strategic Management Journal, vol. 22, no. 3, pp. 197-220, 2010.

[6] J. Huang, J. Ling, and J. Yang, "Key successful factors in knowledge transfer during M\&A in traditional industries: An empirical study," Journal of International Technology and Information Management, vol. 21, no. 4, pp. 43-65, 2012.

[7] Z. Zhang, M. Gao, and H. Wang, "Research on the impact of relative knowledge scale on the innovation performance of M\&A in manufacturing enterprises," Soft Science, vol. 1, pp. 57-61, 2018.

[8] J. S. Harrison and M. A. Hitt. "Synergies and post-Acquisition performance: Differences versus similarities in resource allocations," Journal of Management, vol. 17, no. 1, pp. 173-190, 1991.

[9] A. Seru. "Firm boundaries matter: Evidence from conglomerates and R\&D activity," Journal of Financial Economics, vol. 111, no. 2, pp. 381-405, 2014.

[10] T. R. Zenger and S. G. Lazzarini, "Compensating for innovation: Do small firms offer high-powered in-centives that lure talent and motivate effort?" Managerial \& Decision Economics, vol. 25, no. 6, pp. 329-345, 2004.

[11] R. Kapoor and K. Lim, "The impact of acquisition on the productivity of inventors at semiconductor firms: A synthesis of knowledge-based and incentive-based perspectives," Academy of Management Journal, vol. 50, no. 5, pp. 1133-1155, 2007.

[12] P. Datta and Y. Roumani, "Knowledge-acquisitions and post-acquisition innovation performance: A comparative hazards model," European Journal of Information Systems, vol. 24, no. 2, pp. 202-226, 2014.

[13] M. Makri, M. A. Hitt, and P. J. Lane, "Complementary technologies, knowledge relatedness, and invention outcomes in high technology mergers and acquisition," Strategic Management Journal, vol. 31, no. 6, pp. 602-628, 2010.

[14] H. Tanriverdi, "Information technology relatedness, knowledge management capability, and performance of multibusiness firms," MIS Quarterly, vol. 29, no. 2, pp. 311-334, 2005.

Copyright (C) 2020 by the authors. This is an open access article distributed under the Creative Commons Attribution License which permits unrestricted use, distribution, and reproduction in any medium, provided the original work is properly cited (CC BY 4.0).

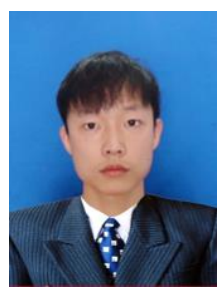

Canjun Chen is a master of business administration at Hohai University of China. He will start his doctorate of management administration in Sep. 2019 at Hoha University. His research interests focus on company innovation, family business. 